Strahlenther Onkol 2013 · 189:262-262

DOI 10.1007/s00066-013-0318-1

Online publiziert: 9. Februar 2013

(c) Springer-Verlag Berlin Heidelberg 2013

\title{
F.-J. Prott
}

Radiologie und Strahlentherapie, BVDST, Wiesbaden

\section{Prof. Dr. Hans-Joachim Thiel zum 65. Geburtstag und zur Würdigung seiner berufspolitischen Tätigkeit}

Der Vorstand des Berufsverbands Deutscher Strahlentherapeuten e. V. würdigt die langjährige und engagierte berufspolitische Tätigkeit seines Mitglieds Prof. Dr. med. Hans-Joachim Thiel.

Herr Prof. Dr. Thiel trat am 11.12.1988 dem Berufsverband Deutscher Strahlentherapeuten als Mitglied bei und prägt seit dem 08.09.2001 bis heute als 1. Beisitzer des Vorstands die berufspolitischen Geschicke des Berufsverbands.

Er hat sich vom Beginn seiner Vorstandstätigkeit sehr gewissenhaft und mit großem Interesse in den Vorstandsressorts Abrechnungswesen, Vertragswesen und Weiterbildung engagiert. Seit 2005 ist Herr Prof. Thiel als Vertreter des BVDST zudem Vorstandsmitglied in der Akademie für Fort- und Weiterbildung in der Radioonkologie der DEGRO und des BVDST und hat hier insbesondere an der Erstellung der Weiterbildungsordnung für die „Fakultative Zusatz-Weiterbildung für interventionelle Strahlentherapie (Brachytherapie)“ und der dazugehörigen Prüfungsordnung mitgewirkt. Seit vielen Jahren zeigt Herr Prof. Thiel weiterhin sehr großes Engagement in der Fortbildung der Sekretärinnen und Assistentinnen aus der Radioonkologie im Bereich der strahlentherapeutischen Abrechnung und schult die Mitglieder der OVIRO e. V. (früher DEGRO-Office AG) alljährig im Rahmen eines 2-tägigen GOÄ- und EBMAbrechnungsseminars in Kassel.

Herr Prof. Thiel wird von seinen Vorstandskollegen ausnahmslos als fachkompetenter und angenehmer Gesprächs- und Diskussionspartner geschätzt.

Der Vorstand dankt Herrn Prof Thiel für seinen bisherigen Einsatz und sein langjähriges Engagement für den Berufs- verband sowie die berufspolitischen Belange der Strahlentherapie und hofft auch nach seinem Eintritt in den wohlverdienten Ruhestand auf eine weitere gute Zusammenarbeit.

Für den Vorstand des BVDST

Franz-Josef Prott, Wiesbaden

\section{Korrespondenzadresse}

Prof. Dr. F.-J. Prott

Radiologie und Strahlentherapie, BVDST

Beethovenstr. 20, 65189 Wiesbaden prott@strahlentherapie-wiesbaden.de 